\title{
The impact and cost of child marriage prevention in rural Burkina
} Faso

Annabel Erulkar

Population Council

Girmay Medhin

Population Council

Eva Weissman

Follow this and additional works at: https://knowledgecommons.popcouncil.org/departments_sbsr-pgy

Part of the Demography, Population, and Ecology Commons, Family, Life Course, and Society Commons, International Public Health Commons, and the Maternal and Child Health Commons How does access to this work benefit you? Let us know!

\section{Recommended Citation}

Erulkar, Annabel, Girmay Medhin, and Eva Weissman. 2017. "The impact and cost of child marriage prevention in rural Burkina Faso." Addis Ababa: Population Council. 


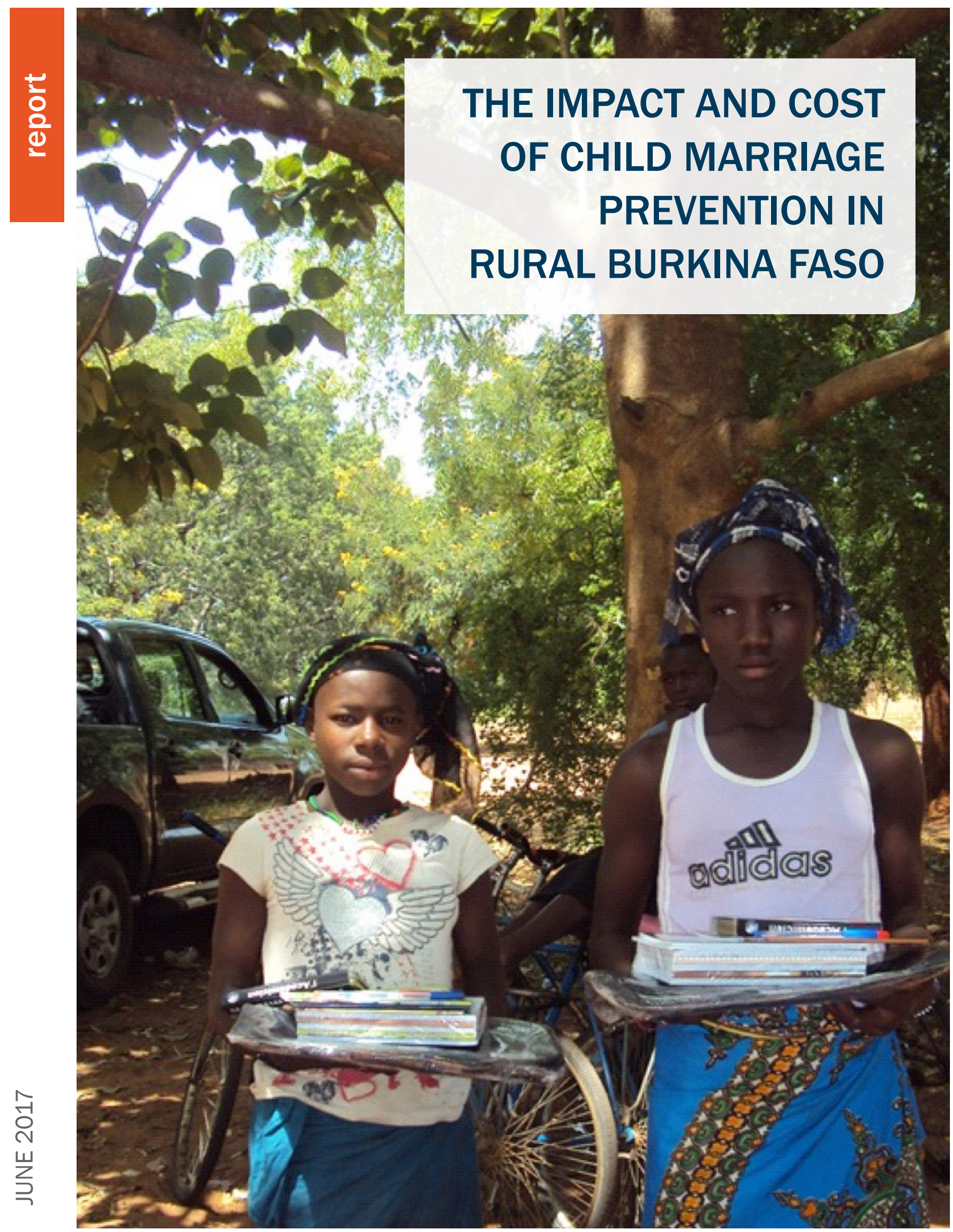




\section{POPULATION}

COUNCIL

Ideas. Evidence. Impact.

The Population Council confronts critical health and development issues-from stopping the spread of HIV to improving reproductive health and ensuring that young people lead full and productive lives. Through biomedical, social science, and public health research in 50 countries, we work with our partners to deliver solutions that lead to more effective policies, programs, and technologies that improve lives around the world. Established in 1952 and headquartered in New York, the Council is a nongovernmental, nonprofit organization governed by an international board of trustees.

\section{Population Council}

Heritage Plaza, 4th Floor

Bole Medhalialem Road

P. O. Box 25562, code 1000

Addis Ababa, ETHIOPIA

Tel: +251-116-631-712/4/6

email: info.ethiopia@popcouncil.org

popcouncil.org

Suggested citation: Erulkar A, Medhin G, Weissman E. 2017. "The Impact and Cost of Child Marriage Prevention in Rural Burkina Faso," Addis Ababa: Population Council.

Photo credits: Population Council

The Impact and Cost of Child Marriage Prevention in Three African Settings. Visit http://www.popcouncil.org/ChildMarriageAfrica for a report and brief and also country reports on Burkina Faso, Ethiopia, and Tanzania.

(C) 2017 The Population Council, Inc.

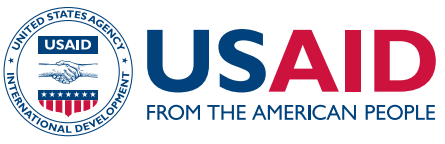

This study is made possible by the generous support of the American people through the United States Agency for International Development (USAID). The contents are the responsibility of the authors and do not necessarily reflect the views of USAID or the United States Government. 


\section{Acknowledgments}

This study was made possible through the hard work and dedication of many individuals and organizations. The project partner Association Munyu des Femmes de la Comoé demonstrated remarkable dedication and commitment in implementing the project in Burkina Faso. Annabel Erulkar was principal investigator for the study. Various Population Council staff and former staff made significant contributions to the study. These include (in alphabetical order): Genework Daba, Kady Dandjinou, Gisele Kabore, Sam J. Lee, Girmay Medhin, Julien Ouedraogo, Tigist Tamrat, and Placide Tapsoba. We are grateful for the support of Burkina Faso government partner Ministère de l'Action Sociale et de la Solidarité Nationale et Ministère de l'Education Nationale et de l'Alphabétisation. Eva Weissman was costing consultant on the study and helped build the capacity of staff and affiliates to collect and analyze cost data. USAID colleagues in Washington and in the country Missions provided invaluable support and guidance, including Mihira Karra, Shegufta Shefa Sikder, Caitlin Thistle, Abdulmumin Saad, Lillian Benjamin, Bakari Traoré, and Jim Parys. Sarah Engebretsen and Thoai Ngo made valuable comments on earlier versions of the report. Finally, we are grateful to the girls and communities in Burkina Faso who took part in the programs and we are hopeful that the research can make a difference in the lives of many more girls in the developing world. 


\section{Background}

It is estimated that globally over 100 million girls will be married during their childhood-before the age of $18^{1}$-in the next decade, and 14 million will be married by age $15 .{ }^{2}$ Child marriage is frequently prevalent in rural locations of poor countries, characterized by low levels of development and limited school and work opportunities. ${ }^{3}$

The negative impact of child marriage spans health, development, and demographic consequences. Ninety percent of first births to girls under age 18 take place in the context of marriage, ${ }^{4}$ and not to unwed mothers as is often assumed. Childbearing typically follows these unions, with early first births being the most risky. Pregnancy and delivery complications are the main reasons for death among girls aged 15 to 19 , and girls who bear children before age 15 are five times more likely to die of pregnancy-related causes compared to older mothers. ${ }^{5}$ Some studies in sub-Saharan Africa suggest that girls who marry early have substantially increased risk of HIV infection-roughly 50 percent higher-compared to their unmarried sexually active peers, ${ }^{6}$ with the excess risk related to frequent intercourse, limited condom use, and husbands who are older and more likely to be HIV positive compared with boyfriends of unmarried girls. ${ }^{7}$

Girls married as children usually enter marriage with low levels of education or no education whatsoever, and limited knowledge and skills to negotiate marital roles. ${ }^{8}$ For example, in Ethiopia, 79 percent of girls who married be- fore the age of 15 had never been to school. ${ }^{9}$ They also tend to have larger age differences with their husbands than those married later, which compromises their power within marriage, including decisions related to family planning (FP), childbearing, and maternal, newborn, and child health (MNCH) services.$^{10}$ Lastly, child marriage is associated with increased total fertility and contributes significantly to population momentum. ${ }^{11,12}$ This occurs because child marriage shortens the time span between generations and increases the number of years that females spend childbearing.

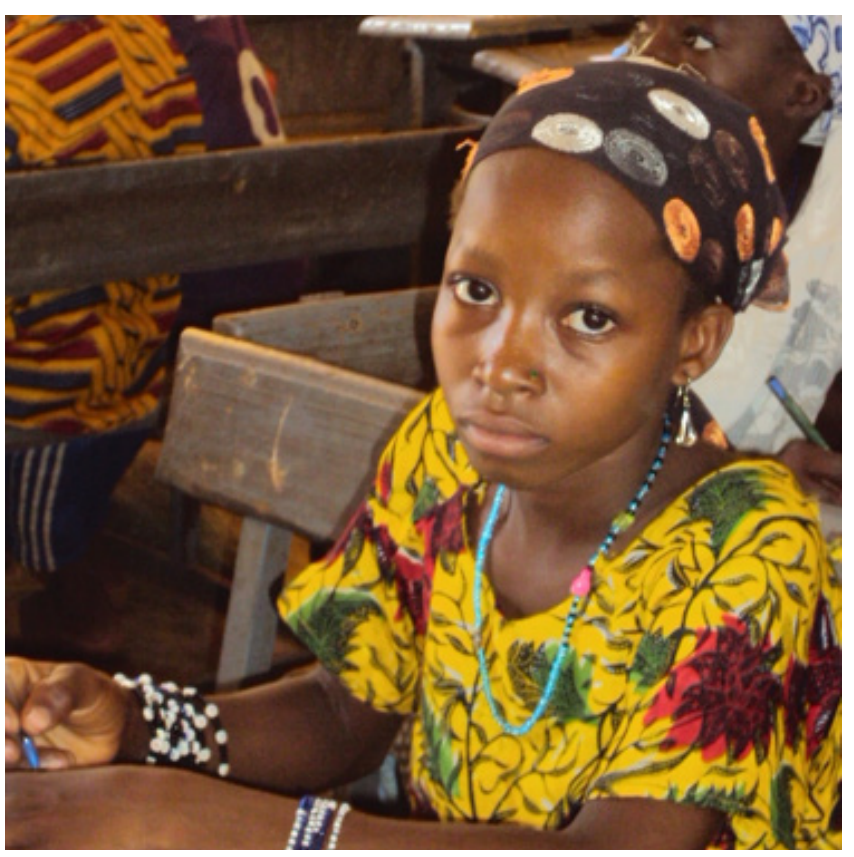

1. United Nations Children's Fund (UNICEF). 2001. Early Marriage: Child Spouses, Florence, Italy: UNICEF.

2. Bruce J. "Child Marriage in the Context of the HIV Epidemic," Population Council: Transitions to Adulthood Brief, no. 11 , Sept. 2005.

3. Lloyd, C, ed. Growing Up Global: Changing Transitions to Adulthood in Developing Countries, Washington, DC: Nat'l Academies Press, 2005.

4. Haberland N et. al. "Early Marriage and Adolescent Girls," Youthnet: Youthlens on RH and HIV/AIDS, Brief no. 15, August 2005.

5. Murphy E, Carr D, "Powerful Partners: Adolescent Girls' Education and Delayed Childbearing," PRB brief, Sept 2007.

6. Clark S, 2004. "Early marriage and HIV risks in sub-Saharan Africa," Studies in Family Planning, 35(3): 149-160. Glynn JR, et al. 2001. Why do young women have a much higher prevalence of HIV than young men? AIDS, 2001; 15 (suppl 4): S51-S60.

7. Clark S, Bruce J, Dude A. 2006. “Protecting young women from HIV/AIDS: The case against child marriage,” Int'I Fam Plan Persp, 32(2): 79-88.

8. UNICEF. 2011. State of the World's Children 2011: Adolescence, An age of Opportunity, New York: UNICEF, February.

9. Erulkar A. 2013 “Early marriage, marital relations and intimate partner violence in Ethiopia," International Perspectives on Sexual and Reproductive Health, 39(1): 6-13.

10. Mensch B, Bruce J, Greene M. 1998. The Uncharted Passage: Girls' Adolescence in the Developing World, New York: Population Council.

11. Raj A, Saggurti N, Balaiah D, et. al. 2009. "Prevalence of child marriage and its effect on fertility and fertility control outcomes of young women in India: A cross sectional observational study," The Lancet, 373(9678): 1883-1889.

12. Bruce J, Bongaarts J. 2009. "The new population challenge," in: Mazur L, ed., A Pivotal Moment: Population, Justice, and the Environmental Challenge, Washington, DC: Island Press. 
In most of the developing world, young people are increasingly marrying at later ages. Among young women in subSaharan Africa, educational expansion has a relatively strong link to delays in marriage age. ${ }^{13}$ Despite an overall trend to later age at marriage, certain social, political, economic, or environmental shocks can be associated with reversals of this trend. For example, rates of child marriage among Syrian refugees in Jordan were found to be increasing perhaps as a household strategy to ensure the safety of the girl or alleviate household stresses; from 2011 to 2013, registered marriages that involved an underage girl increased from 12 to 25 percent. $^{14}$

\section{Child marriage prevention programs}

While one in three girls in developing countries will be married before age 18 , most child marriage prevention programs are small-scale and unevaluated. Lee-Rife and colleagues (2012) undertook a systematic review of 23 evaluated child marriage interventions in developing countries, among which five were in sub-Saharan Africa and many of which were led by the Population Council. While evidence is limited, the review found that the most effective approaches in delaying child marriage were those that empower girls, offer incentives such as conditional cash transfers, and engage communities. ${ }^{15} \mathrm{~A}$ more recent review by Hindin and Fatusi (2014) explored both published and grey literature and found most of the successful programs included a conditional cash transfer, supporting the findings of the earlier review. ${ }^{16}$

For example, the Berhane Hewan program in Ethiopia offered a conditional asset transfer (goat) to families who kept their girls unmarried during the two-year pilot. In addition, girls were given school supplies and communities engaged in community conversations on the harmful effects of child marriage. After two years of intervention, girls aged 10 to 14 in the Berhane Hewan site were one-tenth as likely to be married and three times more likely to be in school, compared to girls residing in the control area. ${ }^{17}$ While the program appeared successful, government implementers were concerned about implementing multi-component projects on a large scale, and there were many questions as to which component of the project brought about the most impact.

Most impact evaluations of community-based programs lack rigorous costing data. This is a particular weakness of cash transfer schemes as programmatic cost would affect the ability to scale up successful interventions for large populations. For example, despite the successful impact of the Berhane Hewan program in Ethiopia, there were lingering doubts about the scalability of providing a $\$ 25$ goat to families (amounting to $\$ 1$ per month for the two-year pilot), an amount which could not be justified in the absence of rigorous costing data. Interventions such as the Zomba scheme in Malawi offered households a conditional cash transfer of between $\$ 4$ and $\$ 10$ per month and offered girls between $\$ 1$ and $\$ 5$ per month. ${ }^{18}$ While Zomba was found to reduce school dropout by roughly 40 percent, it is unclear if such schemes can be feasibly scaled-up to large populations in poor countries, given the monthly expense and the magnitude of payments.

As a result of the limited information on cost and scalability of conditional cash transfer programs, the Population Council and its partners designed a study to determine if simple, cost-contained interventions like those used in Berhane Hewan could be effective at delaying marriage in African countries where child marriage is prevalent. The research includes rigorous costing data, providing evidence for subsequent expansion of successful approaches. This brief outlines the results of the research in the Cascades Region of Burkina Faso.

13. Mensch B, Singh S, Casterline J. 2005. Trends in Timing of the Age at Marriage among Men and Women in the Developing World, New York: Population Council Working Paper no. 202.

14. UNICEF. 2014. A Study on Early Marriage in Jordan in 2014, Amman: UNICEF country office.

15. Lee-Rife A, Malhotra A, Warner A, Glinski AM. 2012. What works to prevent child marriage: A review of the evidence, Studies in Family Planning, 43(4): 287-303.

16. Hindin M. and Fatusi O. 2014. Exploration of Young People's Sexual and Reproductive Health Assessment Practices, Johns Hopkins University, September.

17. Erulkar A, Muthengi E. 2009. "Evaluation of Berhane Hewan: A program to delay marriage in rural Ethiopia," International Perspectives on Sexual and Reproductive Health, 35(1): 6-14.

18. Baird S. Gardein R, McIntosh C, et. al. 2012. Effect of a cash transfer programme for schooling on prevalence of HIV and Herpes Simplex Type 2 in Malawi: A cluster randomised trial, The Lancet, published online February 15, 2012. 


\section{Study Location}

Burkina Faso has the eighth highest prevalence of child marriage in the world. Leraba Province is one of 45 provinces in Burkina Faso and it is located in the Cascades Region, bordering Côte d'Ivoire and Mali. The province is composed of eight communes and has a population of over 124,000 . The region is largely agricultural and cotton is a major economic activity. According to the 2010 Demographic and Health Survey for Burkina Faso, 50 percent of Cascades girls were married by their 18th birthday and 7 percent were married by age $15 .{ }^{19}$ Sixty-four percent of girls in the Cascades Region have never been to school and only 15 percent attain the secondary level.

The Population Council partnered with the Association Munyu des Femmes de la Comoé, a local nongovernmental organization, to implement the interventions at the community level. Association Munyu's mission is to contribute to improving the status of women and the welfare of mothers and children.

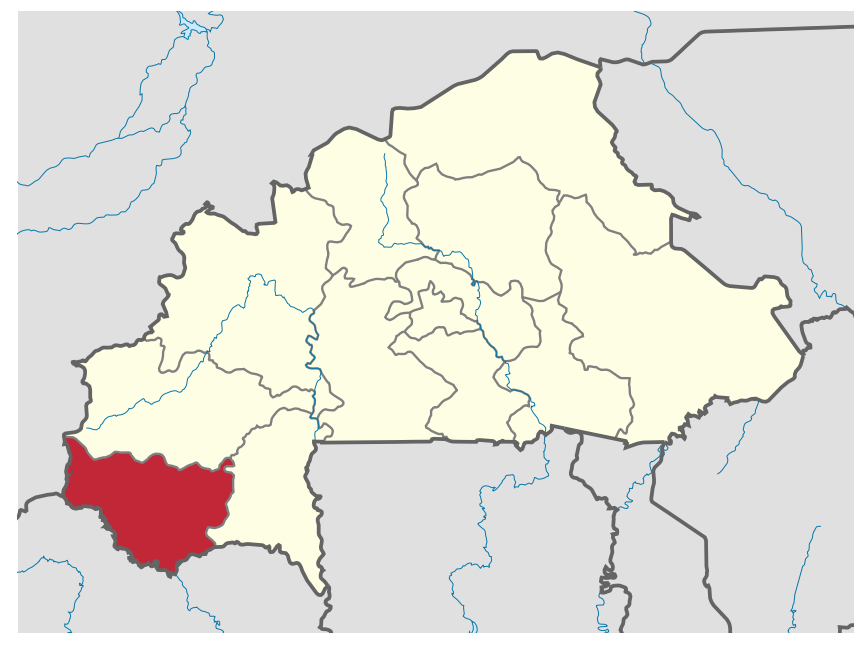

19. Among females 20 to 24 . 


\section{Methodology}

The study compared and tested interventions to delay the age at marriage, in order to identify the most cost effective, scalable minimum package needed to prevent child marriage. We implemented separate child marriage prevention strategies in different communes of Leraba Province, Cascades region.

\section{Interventions tested}

We tested four different interventions to delay the age at marriage including community dialogue, promotion of education, a conditional asset transfer, and a comprehensive model including all the approaches. In two communes of Cascades, we implemented community dialogue on the harmful effects of child marriage in an attempt to address social norms surrounding the practice. A facilitator's guide was developed to standardize messaging on the importance of girls' education and the negative impacts of child marriage. Facilitators were recruited and trained on the facilitation techniques as well as the guide. Discussion groups were formed composed of adult men and women as well as adolescent girls and community leaders. Discussion groups met on a weekly basis for 16 weeks, led by the facilitator. Once groups completed the 16 weeks of discussions, new groups were formed with different community members.

In two communes, schooling was promoted to unmarried girls aged 12 to 17 . Girls who registered for schooling promotion received school materials and school fees with the agreement from girls and their families that they would remain unmarried and stay in school for the two-year duration of the pilot. On an annual basis, girls received about CFA 3,000 (US\$5) in school supplies (notebooks, pens, and pencils) and CFA 2,000 (US\$3.50) in school fees. For girls who did not attend school or could not re-register, nonformal education was provided in collaboration with the Ministry of Education and Literacy. Girls attending nonformal education also received annual school supplies of CFA 3,000 (US\$5) and support for literacy fees amounting to CFA 2,000 (US\$3.50).

In the conditional asset transfer commune, unmarried girls aged 12 to 17 and their families were provided with a goat if girls remained unmarried and in school throughout the pilot program. Two communes included all the project components, or a comprehensive model: community dialogue, schooling promotion, and a conditional asset transfer. In addition, a control commune was included in the study where no intervention took place. Interventions were implemented for 27 months.

\section{Research Design}

This was a quasi-experimental research design with interventions executed in different geographical areas for just over two years. The research was designed to determine the impact of the interventions on the prevalence of child marriage and school attendance at the level of the population. Cross-sectional, population-based baseline and endline surveys were undertaken before the interventions were established and after 27 months of intervention. At each round of survey, 2,500 girls aged 12 to 17 were sampled, 500 per study commune, in order to measure the prevalence of child marriage at the population level, regardless of participation in the interventions. In each study commune, 17 enumeration areas (EAs) underwent a household listing in order to establish a sampling frame; 30 girls and 6 parents were selected for interview in each EA. Female interviewers conducted the interviews. Informed consent was obtained from the parent or guardian of the sampled adolescent and informed assent was obtained from the adolescent girl. Where a girl was married, it was considered that she was an emancipated minor and provided her own consent. In addition, during the course of the interventions,

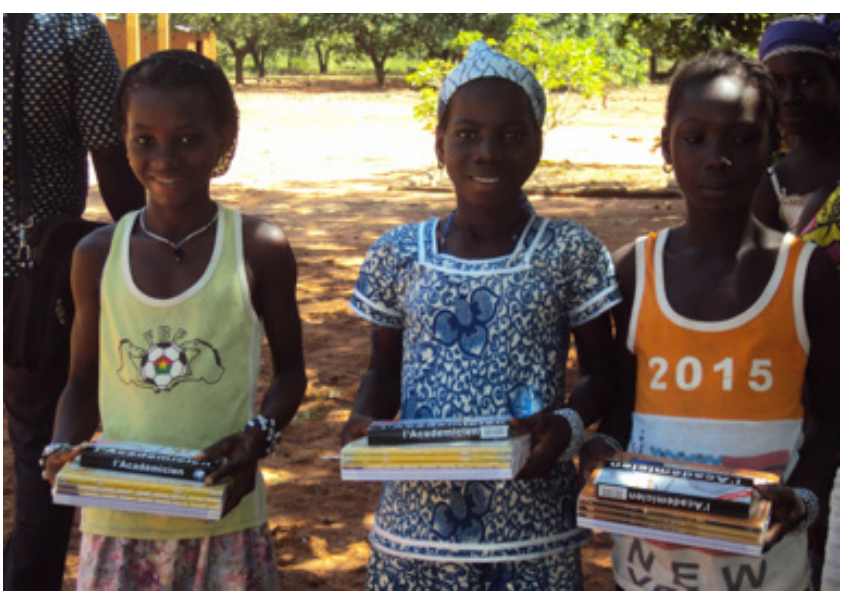


qualitative rapid assessments were undertaken to monitor community perceptions of the different interventions. The study received approval from the Population Council's Institutional Review Board (IRB) as well as the local IRB in Burkina Faso.

At the beginning of the study, a spreadsheet was developed by a costing consultant to enable systematic compilation of all project costs. Cost categories included staff time, office expenditures, training and meeting costs, travel expenditure, and purchase of commodities. Cost data was updated in the spreadsheet on a monthly basis by Association Munyu and Population Council staff. On a yearly basis, costing data was validated by a costing consultant.

Our key outcomes were the percent of girls aged 12 to 17 years who had ever been married and the percent who were currently attending formal or nonformal school or who attended during the previous year. The earlier Berhane Hewan study in Ethiopia demonstrated that child marriage interventions operate differently among younger (12 to 14) versus older (15 to 17 ) adolescents, suggesting the need for subgroup analysis. However, very few Burkinabe girls were married at either baseline (12 girls) or endline (5 girls). As such, we examined marriage trends among respondents aged 15 to 17 only. Poisson regression was used to model the risk ratios (RRs), separately, of being married and attending school in the last year, at baseline and endline. Regressions were adjusted for age, religion, ethnicity, and socioeconomic status (SES). Data were weighted by the number of eligible girls in the household. 


\section{Results}

\section{Study population and exposure to interventions}

At baseline 2,428 Burkinabé girls aged 12 to 17 were interviewed, representing a 97 percent response rate of the desired sample size. At endline, 2,490 girls were interviewed (99 percent of the desired sample size). In addition, 443 and 506 parents of adolescent girls were interviewed at baseline and endline, respectively. Among parents interviewed at baseline, only 13 percent had ever attended school.

The level of participation in the project schemes varied from 20 to 54 percent. The highest level of participation was in the conditional asset transfer arm, where 54 percent of unmarried girls 12 to 17 registered for the scheme. Nearly half (48 percent) of the girls residing in the community dialogue site had attended the meetings or were aware of others attending. Only 31 percent of girls in the education promotion arm registered for the project, while 20 percent of girls in the comprehensive/full site benefitted from the full complement of project components. That exposure to the interventions is lowest in the comprehensive/full model underscores the challenges of implementing complex interventions with multiple components at scale.

\section{Prevalence of child marriage}

From baseline to endline, the percent of girls aged 12 to 17 who had ever been married declined from 15 to 9 percent, respectively, a statistically significant difference. Among girls 15 to 17 , the percent of ever married nearly halved, from 36 to 19 percent. As mentioned, we analyzed changes in marriage prevalence among girls aged 15 to 17 only, as so few girls under age 15 were married. Table 1 shows the risk ratios at endline for girls aged 15 to 17 having ever been married in the study arms compared to the control site after adjusting for age, ethnicity, religion, and socioeconomic status. At endline, girls aged 15 to 17 residing in the community dialogue site had two-thirds less risk $(R R=0.33)$ of being married compared to girls in the control site, a statistically significant difference. No significant changes were detected in the educational promotion arm or the comprehensive model. Those residing
TABLE 1: Adjusted risk ratios (and 95\% confidence intervals) for Burkinabé girls 15 to 17 having ever been married, by project site, with reference to the control arm (weighted $n=2,743$ )

\begin{tabular}{|l|l|}
\hline & Risk ratio $(95 \% \mathrm{Cl})$ \\
\hline Community sensitization & $0.33(0.19,0.60) * * *$ \\
\hline Education promotion & $0.99(0.66,1.49) \mathrm{NS}$ \\
\hline Comprehensive model & $0.77(0.52,1.15) \mathrm{NS}$ \\
\hline
\end{tabular}

Note: Weighted data. Adjusted for age, household assets, and religion NS $=$ Not significant Differences between sites significant at $\star \star * p<0.001$

in the conditional asset site had more than double the risk of being married, both at baseline and endline (results not shown). Additional analysis demonstrated that this site was significantly different from the control site at both baseline and endline, which was impossible to control for in the multivariate models, even after controlling for other background factors.

Quantitative data from parents support that those in the community dialogue arm may have become more amenable to delaying girls' marriage. At endline, parents residing in the communities where community dialogue took place reported the highest ideal age for girls to marry (mean 17.4), compared to 16.0 in the control site, 15.9 in the education promotion site, 15.9 in the conditional asset transfer site, and 17.1 in the comprehensive model. Qualitative monitoring studies underscored the value communities perceived in the sensitization scheme:

Before, we were giving girls in marriage when they started menstruating because we were scared that they would fall pregnant. But since we participated in the discussions, we became aware of the harmful effects of early marriage. In reality, one gains nothing in giving your daughter in marriage early.

- Traditional chief, Community dialogue commune

The "early marriage" project brought about a revolution among girls. When you come back from Côte d'Ivoire with your money to look for a wife, it's difficult now because everywhere people speak of early marriage. - Young male, Community dialogue commune 


\section{School attendance}

Between baseline and endline, the percent of girls 12 to 17 who had attended school in the previous year increased by ten percentage points: from 54 to 64 percent. In multivariate models controlling for age, ethnicity, religion, and socioeconomic status and with reference to the control site, girls aged 12 to 14 residing in the community dialogue site experienced significantly improved school attendance between the two rounds of study. At endline, girls 12 to 14 in the community dialogue arm had a greater chance of being in school $(R R=1.2)$ compared to their counterparts in the control area. As in the analysis with child marriage, the asset transfer arm was not comparable to the control site at both baseline and endline and therefore results are not presented. None of the interventions made a significant impact on school attendance among girls 15 to 17.

\section{Program costs}

The cost of approaches per girl served per year ranged from $\$ 12$ to $\$ 60$. The least expensive models per girl served per year was the community dialogue at $\$ 12$ per girl and the educational promotion arm at $\$ 13$ per girl. The conditional asset transfer estimated at $\$ 33$ and the comprehensive model cost $\$ 60$ per girl served per year. The cost effectiveness-or cost per marriage averted-was calculated for the successful model: community dialogue. The cost per marriage averted among girls 15 to 17 was $\$ 159$ per marriage averted.
TABLE 2: Adjusted risk ratios (and 95\% confidence intervals) for Burkinabé girls being in school in the current and previous years at endline, by age group

\begin{tabular}{|l|l|l|}
\hline & Age 12 to 14 & Age 15 to 17 \\
\hline Community dialogue & 1.18 & 1.06 \\
& $(1.07,1.29) * *$ & $(0.94,1.19)$ \\
\hline Education promotion & 0.99 & 0.92 \\
& $(0.89,1.09)$ & $(0.80,1.05)$ \\
\hline Comprehensive model & 1.07 & 1.03 \\
& $(0.96,1.18)$ & $(0.91,1.15)$ \\
\hline
\end{tabular}

Note: Weighted data ${ }^{1}$ Adjusted for age, religion, ethnicity, and socioeconomic status

$* * \mathrm{p}<0.01$ 


\section{Discussion}

Most intervention research simply measures the impact of approaches on target populations, without regard to the feasibility of scaling up effective interventions. This study contributes to the very limited literature examining impact, cost of interventions, and cost effectiveness. By paying special attention to designing cost-contained interventions, this initiative was explicit in exploring what is feasible, realistic, and scalable within resource-poor settings. Our findings reflect that it is possible to implement simple, costcontained interventions to prevent child marriage and promote schooling.

Results from Burkina Faso suggest that the community sensitization arm was successful in both delaying marriage among girls 15 to 17 and promoting school attendance among those aged 12 to 14 . Moreover, at endline, parents residing in this study site reported the highest ideal age at marriage for girls, compared to the other sites. In contrast to the intervention in Tanzania, the community sensitization intervention was systematically designed and implemented and reached a significant proportion of the eligible population, including girls themselves. Results related to the conditional asset transfer approach were inconclusive in Burkina Faso owing to the fact that this site was not comparable to the control site at both baseline and endline, inherent differences we were not able to control for in the analysis.

In Burkina Faso, unintended pregnancies frequently hastened the arrangement of an early marriage. In settings where adolescents are sexually active outside of marriage, family planning services and information should be accessible. In all settings, knowledge of contraceptives and family planning services, and awareness of fertility should be promoted among adolescents. A focus on schooling, family planning, and fertility awareness can reduce vulnerabilities to child marriage.
Following this study, Population Council and partners are exploring upscaling successful approaches, while continuing to monitor cost and explore programmatic impact in a range of cultural settings. We will assess locations where child marriage is the most prevalent in order to maximize the cost effectiveness of interventions. In addition, we will explore the acceptability and upscaling of the community dialogue approach in a different cultural setting in Burkina Faso: the Est Province. 
